\title{
O ESTÁGIO DE ATENDIMENTO NOS ANOS INICIAIS: EXPERIÊNCIA COM PLANTÃO PSICOLÓGICO
}

\author{
Psychological practicum by early years students: experience through psychologi- \\ cal attendance
La practica de atendimiento en los años iniciales: la experiencia de estudiantes en jornada psicológica

\begin{abstract}
Resumo: Este artigo discute a experiência de quatro plantonistas em seu primeiro estágio de atendimento em projeto de plantão em clínica-escola universitária, no terceiro semestre do curso. Os relatos revelaram como o plantão se organizou para cuidar destes estudantes, bem como cada estagiário conduziu-se de modo singular ao longo do estágio. Evidenciou-se que o plantão abarca múltiplos dizeres dos estudantes como possibilidade de propiciar um aprender pela experiência. Convocados pela atenção psicológica dos supervisores, os saberes dos plantonistas mostraram-se incorporados em seu agir, surgindo nas narrativas contadas. A formação surgiu como formar-ação, pela aprendizagem significativa como via privilegiada de constituição do saber de ofício do psicólogo. A investigação destacou a relevância deste estágio ocorrer nos semestres inicias pelo modo como estagiários apresentaram uma compreensão pertinente de plantão nesta perspectiva. Manifesta-se a urgência da clínica-escola contemplar projetos que diferenciem serviços de atenção às demandas da clientela.
\end{abstract}

Palavras-chave: Plantão psicológico; Fenomenologia existencial; Currículo; Aconselhamento psicológico.

\begin{abstract}
The present investigation intended to explore how four students experienced their first practicum in the university project of Psychological Attendance, from the second year of the Psychology Course. It revealed how that practicum is organized to take care of the student, as well as how the project showed itself as singular, allowing the students' narrative for this investigation. It was possible to comprehend how the psychological attendance opened to the participants many possibilities to learn through experience, by learning in action. At the same time, by the supervisors' careful psychological attention, the students referred how they incorporated such knowledge in their acting by their reflexions about the experiences at the supervisions as well as with clients. It revealed the possibility of significative learning in action as pertinent to comprehend the meaning of psychologist's attention, even when the practicum occurs for Psychology freshmen students. This investigation points to the urgency to changes in the curriculum of Psychology courses in order to contemplate projects that open new possibilities, directing them to the clients' actual needs.
\end{abstract}

Key-words: Psychological attendance; Existential phenomenology; Curriculum; Counseling.

Resumen: Este articulo discute la experiencia de cuatro estudiantes que iniciaron su primera practica de atendimiento en jornada, en el tercer semestre de la carrera. Los relatos revelan como se organizo la jornada para cuidar del estudiante. Por otro lado, el proyecto mostro como cada practicante se comporto de manera singular a lo largo de la practica. Se evidencio que la jornada abarca múltiples posicionamientos de los estudiantes, como posibilidad de propiciar un aprendizaje por medio de la experiencia. Convocados por la atención psicológica de supervisores, los saberes de los participantes de la jornada se muestran incorporados en su forma de actuar, siendo difícil hablar sobre esto, pero surgiendo en las reflexiones e historias contadas. En este sentido la formación surgió como formar-accion, por el aprendizaje significativo como vía privilegiada de la constitución del saber del oficio del psicólogo. Así, la investigación destacó la relevancia de que esta practica sea realizada en los semestres iniciales por el modo como los practicantes presentan una comprensión pertinente de la jornada en esta perspectiva. Por esa vía se manifiesta la urgencia de la clínica-escuela, de contemplar proyectos de practicas que diferencian servicios de atención a las demandas de la clientela, en su amplitud.

Palabras clave: Jornada psicológica; Fenomenología existencial; Currículo de enseñanza superior; Consejería psicológica. 


\section{A proposta de estágio em plantão nos semestres iniciais}

Os debates sobre formação e currículo em psicologia ocorrem desde a regulamentação da profissão e acompanharam o processo de consolidação desta no país. Com a promulgação das diretrizes curriculares para os cursos de psicologia (CES/CNE, 2004), diversos cursos passaram a discutir os respectivos projetos pedagógicos.

No artigo $21^{\circ}$ destas diretrizes, por exemplo, afirma-se ser "recomendável que as atividades do estágio supervisionado se distribuam ao longo do curso.” (CES/CNE, 2011, p. 19). Neste contexto, abre-se a possibilidade de ofertá-las já a partir dos anos iniciais da graduação. Isto é uma indicativa de que os estágios de atendimento não necessariamente precisavam mais se iniciar no quarto ano da graduação ( $8^{\circ}$. semestre), consolidando a idéia de núcleo comum, a princípio mais flexível do que o currículo mínimo. Este núcleo comum da profissão ainda tem como habilidades exigidas a realização de "várias formas de entrevistas com diferentes finalidades e em diferentes contextos", bem como, "descrever, analisar e interpretar manifestações verbais e não verbais como fontes primárias de acesso a estados subjetivos" (CES/CNE, 2011, p. 19).

Referência no psicodiagnóstico interventivo, Yehia (1996) considera a intervenção psicológica em atendimento uma atividade complexa, na medida em que requer do estagiário flexibilidade, improviso e recurso ao seu saber de ofício, compreendido aqui como mescla indissociável entre as teorias incorporadas e a experiência pessoal. Deste modo, ela não chega a considerar que os estágios possam começar nesse período inicial. Contudo, a tradicional estrutura dos cursos, ao priorizar o ensino da teoria nos anos iniciais e ignorar outras propostas metodológicas, não prepara o estudante para a complexidade de seu ofício. Disso resultaria, que o estudante se torna mero aplicador de saberes psicológicos já reconhecidos e, por sua vez, “o cliente é utilizado como uma espécie de cobaia para a aprendizagem" (Yehia, 1996, p. 111).

Já naquela época, esta autora propunha a ideia de confrontar o aluno com situações de "encontro com a alteridade" desde o primeiro ano. Ela enfatiza a pertinência de criar situações nas quais os estudantes possam aprender a partir da experiência. Isto significa deparar-se com o diferente, de modo a reconhecer e repensar pressupostos, perceber a incompletude das teorias, além de apropriar-se da sensibilidade como possibilidade de comunicação de sentido.

Neste sentido, a pesquisadora se aproxima das considerações de Figueiredo (1993) que, reconhecendo a diversidade constitutiva do psicólogo, se lança em um esforço de traçar alternativas a esta multiplicidade. Tal autor propõe "caracterizar o psicólogo, em qualquer contexto que trabalhe, como 'profissional do encontro' (...) assinalando o fato de que o lidar com $o$ outro (indivíduo, grupo ou instituição) na sua alterida- de faz parte de nossa atividade cotidiana." (Figueiredo, 1993, p. 93).

Assim, não basta ao psicólogo reconhecer o diferente no outro, mas denunciar a crença em uma identidade estável e igual a sua própria representação. Além disso, é necessário ele também assumir-se multiplamente constituído e descentrado, revelando-se como desconhecido para si mesmo. É no reconhecimento desta alteridade constitutiva - a existência do outro em mim - que se encontra a condição mesma do trabalho do psicólogo.

Destarte, poderia um estágio em clínica-escola ser uma via para se criar estas referidas situações cruciais e desafiadoras a partir do segundo ano $\left(3^{\circ}\right.$. Semestre) do curso de psicologia? Quais cuidados devem ser considerados para conduzir tal proposta?

A proposta deste artigo é compreender a experiência do estagiário a partir da sua participação no Projeto de Atendimento em Plantão Psicológico (APP), realizado em clínica-escola universitária.

O projeto de plantão vem sendo disponibilizado como estágio a estudantes do segundo ano da graduação, desde 2007. Realizado na clínica-escola de uma universidade ocorre uma vez por semana, disponibilizando atendimento psicológico a qualquer um que o procure, sem necessidade de inscrição prévia, das $17 \mathrm{~h}$ às $21 \mathrm{~h}$. $\mathrm{O}$ atendimento pode ser individual, em casal $\mathrm{e}$ em família. Crianças e adolescentes só podem ser atendidos com a presença dos responsáveis legais.

A supervisão é realizada in loco, ou seja, durante o próprio período de plantão, em salas reservadas. Ela pode ser individual ou ocorrer coletivamente, com a contribuição de mais de um supervisor e dos demais colegas presentes.

O plantão "surgiu como uma tentativa de atingir e beneficiar uma parte da população que necessita de ajuda psicológica e que, nem sempre, no momento da emergência da queixa, é por ela contemplada." (Morato, 1999, p. 33-34). Mahfoud (1999, p. 146) o considerava uma "técnica de atendimento breve" e, de fato, em muitas instituições ele se apresenta como uma sequência de quatro a cinco atendimentos. Já Morato (1999, p. 34) considerava que o encontro poderia ser único e mesmo nesta situação, o cliente poderia se beneficiar do atendimento, conseguindo "uma visão mais clara de si mesmo e de sua perspectiva frente à problemática que vive e gerou o seu pedido de ajuda. (...) com a participação efetiva de ambos: cliente e conselheiro-psicólogo".

Inicialmente constituído em clínicas-escola, o plantão por sua pronta oferta de atendimento sem necessidade de triagem, diagnóstico, encaminhamento ou filas de esperar, logo se expandiu como modalidade de prática para outras instituições.

Na medida em que a prática psicológica se desvelava em cada cenário distinto, a proposta de implantação do plantão nos moldes da clínica-escola mostrou que, diante dos desafios e impasses que ocorriam no cotidiano de cada instituição, o plan- 
tão, embora se apresentasse como serviço à instituição demandante, foi compreendido cada vez mais como uma metodologia de intervenção clínica. Por tal termo, compreende-se que o plantão abarcava simultaneamente um modo de conhecer a instituição a partir de uma atitude cartográfica ${ }^{1}$, bem como de, já nesse conhecer, criar espaços de escuta e cuidado das singularidades ali presentes, pela atenção psicológica propiciada pelos estagiários.

O termo "atenção psicológica" passou a se referir ao modo do psicólogo estar atento e disponível àquilo que, no outro, demanda por expressão, trânsito, diálogo... testemunho. Neste sentido, o "atender" e o "cuidar" disponibilizados pautam-se, sobretudo, no oferecer guarida, abarcar e conter o sentido de uma experiência que, de outro modo, poderia permanecer como ausência de sentido ou cair no desamparo. Mais do que um esforço no sentido de dirigir-se a, trata-se de estar presente como abertura para deixar vir, aproximando o plantão da perspectiva fenomenológica existencial (Pompeia \& Sapienza, 2011). Uma vez abrigado, cabe ao cliente retomar a sua trajetória de des-continuidades e atravessamentos, podendo ou não retornar, mas considerando o plantão uma referência de cuidado às suas questões.

Como Figueiredo e Santi (2003, p. 72) apontam, "num mundo em que, concretamente, há cada vez menos liberdade e cada vez mais massificação", esse modo de ser psicólogo implica necessariamente uma postura ética de denúncia dos mecanismos de "domesticação dos indivíduos", ao atentar para a singularidade de cada um, como modo único e imprevisível de realização de sentido do ser.

Diante destas reflexões e com o novo currículo em andamento, o referido laboratório universitário implantou o Projeto de Atendimento em Plantão Psicológico (APP) na clínica-escola em 2007. O estagiário era convidado a fazer uma residência em plantão, o que implicava não somente atender e passar pela supervisão, mas se responsabilizar, semanalmente, pela abertura e fechamento do serviço, participar de outras supervisões, fazer registro de prontuários, cadastrar conveniados e montar uma rede de apoio para eventuais encaminhamentos (Morato, 2009). Com esta proposta, o sentido de plantão, bem como o de psicoterapia e a própria formação, poderiam ser discutidos e repensados junto aos plantonistas.

Nesta perspectiva, este projeto disponibilizou-se para receber estudantes dos semestres iniciais, de modo a re-situar a curiosidade inicial desta pesquisa: como ocorreu a experiência de estágio a esses estudantes?

\footnotetext{
1 Historicamente "cartografia" se refere à fronteira entre as ciências humanas e exatas, no sentido de que cartografar é mapear mundo, para desvelar territórios habitados e não meramente demarcar terreno. Para a equipe do laboratório, cartografar significava esse momento inicial, mas continuamente retomado de conhecer o território, desvelar pressupostos, surpreender-se com imprevistos e, simultaneamente, dar-se a conhecer, desconstruindo, principalmente, ideias pré-existentes sobre o que seria o trabalho do psicólogo (Aun, 2005).
}

\section{Explicitação do percurso metodológico}

Na investigação deste tema, acompanhei os estagiários do projeto de APP durante um período de dois anos e três meses. Quatro estudantes de graduação foram convidados para entrevistas individuais. As entrevistas foram realizadas enquanto os estudantes ainda estavam no estágio, depois de terem cumprido um ano de atividades no plantão. Foram duas entrevistas com cada estudante, marcadas fora do horário de plantão, de acordo com a disponibilidade dos participantes. Na primeira trabalhou-se a partir de uma pergunta disparadora e dos temas e histórias que surgiram. A segunda entrevista ocorreu um mês após a primeira e visava esclarecer e aprofundar termos, ideias e sugestões que ficaram ambíguos ou superficiais em um primeiro momento.

Após o aceite, os participantes assinaram o Termo de Consentimento Livre e Esclarecido. A escolha partiu de duas premissas: 1) terem realizado o primeiro estágio de atendimento neste projeto, a partir do terceiro semestre da graduação; e 2) terem permanecido no projeto ao menos por um ano.

As entrevistas se abriram a partir da seguinte pergunta: "Como está sendo a sua experiência de estágio neste projeto de plantão?”. O modo da pergunta buscou convidá-los a explicitarem situações do estágio que consideravam pertinentes a sua formação.

No decorrer de cada entrevista, esforcei-me para, simultaneamente, aproximar-me e distanciar-me do que era dito. Como já fora supervisor desses estagiários, a aproximação parecia evidente e, por isso perigosa. Nesse lugar, a convivência semanal com os estagiários pode ocultar "mal-entendidos" em relação àquilo que eu buscava compreender. O perigo de encontrar o "já sabido" é maior diante da cumplicidade compartilhada a partir dos atendimentos e supervisões. Por outro lado, a proximidade que pode gerar uma "cegueira", também pode auxiliar o desvelamento do sentido da experiência, pois a intimidade propícia para o testemunho de certas situações já se encontra presente pelo convívio.

Neste sentido, a hermenêutica filosófica proposta por Gadamer (1997) auxiliou a legitimação desta proposta investigativa. Pela noção de tradição, pode-se afirmar que a compreensão prévia de mundo constitui o ponto inicial a partir do qual o investigador apropria-se de novas significações, ampliando seu horizonte de sentido. É pertinente a este processo investigativo refletir a partir do que vai sendo explicitado, em busca de des-naturalizar os saberes tradicionais presentes na compreensão prévia e, simultaneamente, constituir novos saberes, numa ampliação do horizonte compreensivo do investigador.

Além disso, o pesquisador deve "deslocar-se" das noções prévias rumo àquilo que busca compreender. O deslocamento, que ocorre no campo da linguagem ${ }^{2}$,

2 Refere-se à dupla noção de que a linguagem é constituída a partir da ação entre homens, constituindo-a e sendo por ela constituído. 
orienta-se para a fusão de horizontes de sentido, meta concebida e noção reguladora, mas nunca totalmente alcançada. É preciso que o investigador esteja aberto a deixar-se contrariar e se transformar pela experiência que se apresentou. Assim, o que já é conhecido pode ser modificado e encaminhar outros saberes.

Após o processo de realização das entrevistas, busquei em autores como Pierre Bourdieu (1997) e José Carlos Bom Meihy (1991), os fundamentos para uma transcrição pertinente do registro oral.

Segundo estes autores, a passagem do oral ao escrito, assim como o seu reverso, demanda transformações necessárias, pois não se pressupõe que o discurso fale por si mesmo. Neste sentido, pode se considerar a transcrição como já uma interpretação, na trajetória do esforço compreensivo. Os tiques de linguagem, as repetições desnecessárias e as frases confusas devem ser suprimidos de modo a respeitar o interlocutor e facilitar a compreensão do leitor.

Posteriormente, transformei as transcrições em textos, anulando a voz do entrevistador para dar espaço à voz do narrador, incorporando as perguntas no discurso do entrevistado. A textualização visou a reorganização do discurso para fazê-lo literariamente compreensível e agradável ao leitor. A partir daí, passei à transcriação, processo que "implica evidenciar o narrador em sua essência maior. $\mathrm{O}$ que interessa é jogar luzes na narrativa e não nas intermediações que devem, como os andaimes, cair desde que procedido o trabalho" (Meihy, 1991, p. 33).

Segundo Benjamin (1994), a narrativa é um modo de transmissão de experiência de geração em geração, configurando-se como o legado transmissível da tradição-memória que rompe o tempo de imediatamente presente, instaurando a dimensão existencial com presente e passado articulados pela busca por sentido (Cardoso, 1997). Além disso, ela não é somente um modo de apresentar a experiência, mas de sua própria constituição, fundamentando-se na linguagem como efetivação do real (Critelli, 1996). Ela se desenvolve numa temporalidade, enquanto articulação tempo-espaço, oferecendo-se como movimento histórico de sedimentação e reconstrução da memória.

Neste percurso, optei por construir um texto narrativo a partir de trechos de cada relato. Utilizei quatro nomes fictícios para relacionar cada trecho com o respectivo entrevistado, de modo a identificar a fala de cada estudante, sendo eles: Caio, Beatriz, Luiza e Mauro.

A cada trecho citado, busquei desvelar significados possíveis, levantando questionamentos. Por esta via, a narrativa não buscou a construção de conceitos, mas trabalhou com a ação de nomear, a partir da qual o sentido de uma investigação pode se revelar, efetivando uma compreensão. A nomeação é "o ato de produzir figurações, imagens, através de um fluxo narrativo conduzido pela memória, que descongela o inominado e que neste movimento se abre para novas figurações" (Cardoso, 1997, p. 179). Deste modo, a narrativa apro- ximou-se das considerações presentes em Gadamer, pois conduzir-se pela memória é desvelar as compreensões prévias da tradição, bem como abrir-se para o não-sabido presente no esforço compreensivo.

Na tessitura dessa trama, o projeto de plantão se deu a ver em sua constituição, a partir de como os entrevistados realizaram uma compreensão da proposta de estágio, apontando para uma dimensão coletiva. A narrativa foi então se compondo como trabalho em co-autoria, na articulação dessas vozes com a minha tentativa de compreensão. Deste modo, configurou-se uma constelação de dizeres que buscou apresentar uma compreensão da singularidade de cada relato, bem como destacar possíveis significados da dimensão coletiva presente no atravessamento das falas.

\section{0 estágio a partir dos seus protagonistas: experiên- cia em ação}

Inicialmente os estagiários se mostraram encantados com a oferta de estágio a partir do segundo ano. Mauro afirmou que escolhera "psicologia por causa da clínica e achava muito ruim ter que esperar quatro anos para atender". Além disso, "foi bom atender no segundo ano e ver que nenhuma teoria precede o encontro, pois é nisso que acredito”.

Beatriz comentou que " a parte boa é participar de atendimento e entrar em contato com a prática e aprender de maneira mais solta, antes de ter aula de fenomenologia e compreender a teoria".

Luiza esclareceu que "o aprendizado aqui é na prática, é no fazer. É diferente daquele com o qual estamos acostumados na faculdade. Você não lê o texto e basta. Você conversa na supervisão sobre aquilo que você fez no atendimento e constrói um saber a partir desta prática.”. Embora tal ideia possa remeter a uma proposta de aprendizagem pela experiência, dizer que "o aprendizado aqui é na prática, é no fazer", pareceu soar mais como slogan, algo irrefletido e vazio.

Por sua vez, Caio disse que "já pensava que essa oportunidade de atendimento clínico nos primeiros anos é fundamental". Ele ainda afirmou que "só a teoria pela teoria não consegue direcionar os meus interesses. É interessante entrar em contato com algo sem primeiro ter uma teoria e aqui me reforçou essa opinião.

Ao que Caio se refere quando diz "teoria pela teoria"? Seria um conhecimento desvinculado da prática, sinalizando uma crença na separação entre teoria e prática?

Os trechos acima parecem evidenciar como os plantonistas ansiavam por um estágio com essa aparente ausência de teoria e, ao comentarem sobre o plantão, fica a impressão de reafirmarem interesses e opiniões prévios. Será que eles procuraram o já esperado e se mantiveram no já conhecido? Estaria a perspectiva fenomenológica existencial sendo compreendida como justificativa para um estágio descompromissado de um aprofundamento teórico problematizador do atendimento em plantão? 
Aos poucos, ao contarem os seus primeiros atendimentos, o encantamento inicial cedeu lugar a incômodos. Caio contou o seu primeiro atendimento em plantão da seguinte forma:

Eu atendi uma mulher que estava bastante fragilizada, tanto é que na semana seguinte ela foi encaminhada para o hospital universitário. (...) eu fiquei sem saber como agir diante de uma pessoa assim! Por mais que eu tivesse vontade de perguntar algo eu ficava com medo de que o que eu dissesse fosse muito devastador para ela... eu não sabia o que poderia acontecer. Então realmente não falei nada, fiquei mais cauteloso. Depois eu vi que a fragilidade estava mais em mim do que na mulher... eu também estava com medo de colocar o que estava vendo, pois não entendia porque eu via aquilo.

Na fala de Caio evidencia-se o conflito entre a vontade e o medo. Havia uma preocupação e um temor em relação ao estado da cliente. Entretanto essa atenção dirigida à fragilidade da cliente parecia encobrir a crença de que ele era detentor de uma fala, cujo poder conseguiria dilacerar o mundo da moça. A imagem de um psicólogo poderoso encobria a fragilidade de um aprendiz que não entendia muito o que estava acontecendo e não sabia ao certo como agir. E mesmo quando Caio pareceu entender, ficou a dúvida sobre a própria percepção. Pareceu então que o medo já não era mais o de possuir um poder devastador; pelo contrário, transformou-se na sensação de impotência de pouco se conseguir fazer por aquela mulher a não ser encaminhá-la a outro local.

O relato de Luiza trouxe uma situação semelhante: "No meu primeiro atendimento, a pessoa tomava remédios psiquiátricos e estava muito desorganizada. (...) eu fiquei meio confusa junto com a pessoa e saí com uma sensação de que precisava ser salva daquilo!

Se o relato de Caio trouxe a imagem do psicólogo onipotente, a fala de Luiza revelou outro medo: o da mistura com o cliente, lançando a estagiária no caos diante do desconhecido. Compreendo que aventurar-se para além das próprias crenças pode conduzir a uma perda de sentido. Mesmo que momentaneamente, tal perda pareceu ser vivida como um afogamento, um aniquilamento de si. Assim, Luiza mencionou precisar "ser salva" desta situação trágica. Neste sentido, o movimento do estagiário de atrelar-se ao já conhecido pode ser compreendido como um modo de tentar evitar essa experiência desorganizadora?

$\mathrm{O}$ relato de Beatriz, apresentou uma situação bem diferente:

No meu primeiro atendimento me senti um vaso! Eu atendi com um colega já formado e, enquanto eu tentava perceber alguma coisa, ele ia de raciocínio em raciocínio e eu não acompanhava! Foi tudo muito rápido! Algumas coisas eu percebia e achava o máximo como ele devolvia, mas muitas eu nem chegava a pensar direito.

Ao situar-se na cena como um enrijecido objeto, Beatriz pareceu expressar o seu descontentamento, pela ironia. "Um vaso" é qualquer coisa de insignificante num atendimento, comunicando uma ausência presente. Suas tentativas de entender o que se passava ficaram à míngua, sem maiores considerações. Como observadora, ela deu a impressão de estar impedida de aprender a partir do agir próprio. O silêncio aqui talvez seja mais cruel, por nem se chegar a reconhecê-lo como tal.

Outro elemento que merece destaque neste trecho é a entrada dos estagiários com psicólogos formados ou colegas dos últimos semestres, formando duplas para o atendimento.

Luiza e Mauro referiram-se à "segurança" de entrar com "alguém mais experiente". Na fala da estagiária, "foi ótimo porque aos poucos ganhei a segurança de que precisava. Primeiro eu fiquei olhando, depois me permiti dizer alguma coisa". Já para Mauro, "é bom porque passa uma segurança. Antes de entrarmos ela conversou comigo e me deixou muito à vontade para falar o que quisesse e até para sair do atendimento se desejasse... ela me tranquilizou".

Estes trechos transmitem a ideia de que atender junto a um colega mais experiente "passa" uma segurança e, aos poucos, o estagiário constrói a sua própria. Neste sentido, Mauro percebeu que uma atitude importante da sua colega foi estar atenta a como ele se encontrava e mostrar-se disponível para conversar sobre o que quisesse.

O relato de Caio também destacou esse cuidado ao estagiário iniciante:

Quando a gente atende em dupla dá para ficar mais quieto e observar... e é bom ficar em silêncio porque você percebe outras coisas... só que agora eu devolvo o que percebo, antes eu deixava passar... eu passei a arriscar mais. (...) se eu falar besteira acontece, mas essa tentativa de mostrar o cuidado é mais importante do que pensar se eu falei besteira. Agora é ficar atento para as próximas vezes.

De modo distinto ao de Beatriz, situada como um "vaso" no atendimento, o relato de Caio transmitiu a sensação do repouso pensativo. Ele aproveitou a presença do colega para estar de modo mais confortável, embora atento. Nesse sentido, o atendimento em dupla propiciou que ele confiasse em sua percepção e arriscasse mais, pois, conforme ele mesmo disse, tentativas malogradas também indicam um esforço cuidadoso.

Luiza pode contribuir na compreensão das duplas de atendimentos a partir do seu lugar diferenciado, por ter se tornado uma estagiária que acolhe os iniciantes: "Muitos não falam por não verem esse espaço ou por ele não se abrir. Eu tento abrir esse espaço no próprio atendimento. Por exemplo, se um amigo começa a falar eu o deixo seguir em frente: "Vai lá, desenvolve!". 
O estagiário pode silenciar por não perceber uma abertura, mas o colega também pode desatentar em disponibilizar esse espaço: descuido de ambos. Tal consideração é interessante, pois ao estagiário, que coube decidir como e quando se colocar, também competiu co-responsabilizar-se pela sua condução no estágio. Deste modo, pode-se compreender que o plantão foi apresentado aos estudantes a partir da própria atenção e disponibilidade ao outro que o companheiro de dupla dava a ver, como reveladoras de um modo de ser psicólogo. Neste sentido, diferente de forçar uma participação, Luiza convidou o colega a participar do diálogo com o cliente, de modo aparentemente descompromissado.

Outro movimento da estagiária foi o de "deixar" o colega "seguir em frente" na sua fala. Ela legitimou que ele conduzisse sua intervenção sem ser interrompido em suas considerações. Assumindo que ela talvez possua "mais experiência", o que ela fez com esse "poder" foi colocar-se a serviço do estagiário. Esta atitude propiciou ao estudante perceber-se como co-autor no atendimento e descobrir-se como psicólogo.

Por essa via, Beatriz revelou uma dificuldade no atendimento em dupla:

Eu não pensei em trabalhar em dupla, mas em esperar e respeitar a vez do outro. Eu não aproveitei a deixa do outro para esclarecer pontos meus. Quando você vai na mesma direção do colega é tranquilo pontuar, mas se isso não acontece é bom você aproveitar o que ele está dizendo para colocar a sua ideia.

Realizar um trabalho em conjunto, no qual cada plantonista dá sequência ao raciocínio do outro, não é tão simples quanto parece. Na fala desta estagiária, não houve uma sequência ou complementação de raciocínios, mas a sobreposição de diferentes impressões. Como contemplar a alteridade quando a singularidade parece se impor? Mário Quintana (1988, p. 35) provoca: "A gente diz uma coisa, o entrevistador entende outra e o leitor entende outra. Enquanto isso, a coisa propriamente dita fica pensando que não foi propriamente dita”.

Por essa via, Mauro apresentou a seguinte reflexão:

Pode haver olhares diferentes entre dois plantonistas e essa rica divergência ajuda você a abrir os olhos para um caminho que você não enxergava... semelhante à supervisão. Essa divergência pode gerar alguma confusão, mas se você se apoia no que é dito em atendimento, a gama de interpretações é restrita.

Neste trecho é interessante perceber como Mauro aproximou o trabalhoso exercício de atender em dupla com a supervisão. Para ele, a divergência entre pares pode gerar conflitos, mas, sobretudo, é algo fecundo, pois propicia a diferenciação de significados, na busca por sentido.
Neste caminhar, os relatos indicaram a pertinência dos primeiros atendimentos serem realizados em dupla. As falas também apontaram como esse recurso foi pensado a partir dos incômodos que surgiam no cotidiano do trabalho, marcando cuidado aos iniciantes. Diante das vicissitudes reveladas por tal proposta, algum outro auxílio foi disponibilizado?

Caio apresentou uma resposta:

No começo, eu trazia as minhas impressões do atendimento para a supervisão e o sentido se esclarecia, só que a pessoa já tinha ido embora... então não adiantava. Fazia sentido para mim, mas não para a pessoa que veio procurar. O lance do Plantão é que a pessoa virá quando ela sentir que precisa, então não dá para saber se ela vai voltar! (...)

Eu acredito que essa possibilidade de supervisão no meio do atendimento é algo bom porque dá para você voltar e continuar... não fica só você com a compreensão e o cliente já foi embora.

A fala deste estagiário denuncia uma insatisfação de que o que era esclarecido com os supervisores ficava somente entre eles e o cliente já havia partido. Neste sentido, não bastou ao estudante modificar a sua compreensão do atendimento: o sentido maior desta só se realiza quando comunicado ao cliente.

Por essa via, a proposta de intervalo apareceu no espaço de supervisão, no qual os envolvidos começaram a se incomodar com o modo pelo qual o atendimento se realizava. A breve interrupção no atendimento, devidamente comunicada ao cliente, passou a ser denominada de "supervisão de meio". Ela veio a ocorrer da seguinte forma: os supervisores aguardavam na sala de supervisão, sem espelho de observação, e orientavam os estagiários a interromperem o atendimento quando sentissem necessidade e também para discutirem como encerrar aquele encontro. O momento da interrupção ficava a cargo dos estagiários e dependia de cada atendimento bem de como se apresentava o cliente. Alguns atendimentos duravam meia hora e outros passaram de duas horas, pois às vezes se atendiam casais e famílias em plantão. Em média os atendimentos duravam uma hora e meia, contando a escuta e intervenções iniciais, a supervisão de meio e o retorno para fechamento.

Para Caio, esse intervalo possibilitou que a dupla de plantonistas trocasse impressões e recorresse aos supervisores para se re-situarem frente ao que estava acontecendo. É um momento para escutar-se diante daquilo que o cliente apresentou, abrindo incômodos e levantando dúvidas. Desse modo, eles voltavam ao atendimento com uma nova compreensão e podiam dar continuidade diferenciada ao que demandava cuidado.

Mauro revelou outro atendimento em dupla em que as dificuldades foram superadas de modo notável. 
Junto a uma colega, ele atendia uma moça que fora violentada anos atrás e agora contava isso pela primeira vez aos plantonistas:

Ela só se dirigia a minha colega... quando eu falava algo ela fazia uma cara estranha... comecei a me sentir mal lá dentro. Ela falava mal de homens em geral, de não conseguir ficar perto deles e eu comecei a me sentir mal por ser homem! Lidamos com isso na medida em que a minha colega disse que ali estava presente um homem que junto a uma outra mulher foram os primeiros a escutarem o que ela guardou durante quinze anos.

Ao se dar conta do sentido que o mal-estar indicava, a colega de Mauro pontuou que a presença acolhedora do estagiário poderia mostrar-lhe que nem todos os homens são necessariamente maus. Colocada deste modo, tal ideia não coagiu a cliente a aceitar a presença do plantonista, mas propiciou-lhe re-significar a sua experiência junto a um homem. A moça pode lidar com a sua desconfiança generalizada pelos homens na medida em que o estagiário revelou consideração e sensibilidade pelo seu sofrimento.

Ao comunicar esta ideia, a plantonista também possibilitou ao estagiário olhar para o seu incômodo de outro modo, propiciando-lhe perceber a importância e o sentido da sua presença ali. Nessa situação, foi possível olhar para os três ali naquele momento e trabalhar em cima do que estava acontecendo.

Neste sentido, a fala de Caio apontou outra dimensão do estágio: "Para um plantão que não pressupõe uma continuidade é valioso ter pontos de vista diferentes num mesmo momento". O que os relatos dos plantonistas revelaram sobre essa "não-continuidade" do atendimento em plantão?

Caio apresentou uma situação interessante a ser considerada:

Atendi um homem casado que veio ao plantão a pedido de sua amante para decidir com qual das duas mulheres ele ficaria. Ele pedia ajuda para resolver esta situação, mas, por mais que reclamasse, ele falava disso com orgulho! Dava a impressão de um movimento pendular e de que não era algo que ele realmente quisesse resolver. Mesmo sem isso estar muito claro na hora, eu consegui dizer essas impressões para ele e fez muito sentido!

Ao longo do atendimento, Caio teve a impressão de um "movimento pendular": alguém que oscilava de um lado a outro e não conseguia tomar uma posição nem com relação ao fato de ter ido ao plantão. A partir do modo como fora afetado, mesmo sem ter certeza, o estagiário arriscou e pontuou este movimento do cliente sem ter a necessidade de convencê-lo. Ele respondeu à situação sem atender diretamente o pedido: o seu gesto convidou o cliente a lidar com a questão de não conseguir assumir o sentido de estar ali. Ele confrontou o cliente com o modo de ser deste, a partir do que ele percebera. $\mathrm{O}$ gesto do plantonista, ao mesmo tempo em que afirmava, também questionava o cliente, como se dissesse: e agora, como seguir adiante?

Se o plantonista contasse com a ideia de um eventual retorno talvez deixasse passar o momento que se revelou oportuno para ambos. Aliás, será que, em um segundo encontro, tais colocações fariam sentido? Mais ainda... haveria um segundo encontro?

Diante da ideia de que o "plantão não pressupõe uma continuidade", a atitude do plantonista evidenciou uma prontidão em perceber os lugares em que o cliente o colocava e, simultaneamente, situar-se de maneira a devolver uma compreensão de como o cliente se encontrava no atendimento. Por outro lado, houve um cuidado em não ser tomado pela pressa de arranjar soluções às solicitações do cliente. Esta atitude revelou o plantão como oportunidade fecunda para o cliente deparar-se com seu modo de ser situadamente desencontrado, propiciando reflexão. Deste modo, abriu-se uma escuta atenta ao que urgia, demandando sentido.

$\mathrm{O}$ relato de Mauro pode auxiliar ainda mais a compreensão dessa noção de descontinuidade do plantão:

Uma vez, uma plantonista disse a um rapaz que ele parecia um "bebezão" birrento... ele concordou daquele modo meio vazio. Depois, eu o atendi e me veio novamente esta imagem. Então eu disse que me parecia que pouca coisa havia mudado para ele desde a infância. Na outra sessão, o rapaz falou como percebeu, a partir do que eu dissera, que o quarto dele era exatamente igual desde os dez anos de idade. Ele viu um quadro de cortiça com fotos que estava lá há mais de vinte anos e percebeu que não havia mais sentido para aquilo, pois ele havia mudado.

Neste trecho, o rapaz foi atendido por uma plantonista e, retornando ao plantão, passou por outro estagiário. Evidentemente, a troca de estagiários marcou uma ruptura em relação ao encontro anterior. Entretanto, diante dessa proposta, o cliente deu continuidade às suas questões, mesmo com plantonistas diferentes. Deste modo, a partir de como o cliente se apresentava, a sensação de estagnação surgiu novamente ao plantonista. Mesmo com a troca de estagiário, o gesto do cliente indicava a continuidade de algo que o desassossegava, mas ainda permanecia à espera de uma palavra viva que inaugurasse o trânsito de uma comunicação.

Ainda que tivesse um breve conhecimento da situação, Mauro não se limitou a olhar o já visto. Próxima de uma linguagem poética, a fala do estagiário apresentou-se como sugestão plena de espanto que convidou o cliente a estranhar-se no já familiar. Deste modo, ele viu sob outra mirada o que se mostrava difuso e comunicou de outro modo o que demandava esclarecimento. Neste sentido, o abrigo oferecido pelo 
plantão referiu-se à possibilidade do cliente dirigir-se de um olhar às questões para um assumir-se como questão em aberto.

Essa segunda situação aprofundou a compreensão do atendimento em plantão, a partir da noção de "não-continuidade". Por um lado, o estágio enfatiza a ideia de encontro como oportunidade única, com começo meio e fim, desvinculado da noção de processo terapêutico. Entretanto, esse momento singular pode se ater a um atendimento ou desdobrar-se em mais retornos ao plantão. Assim, a partir da compreensão de cada situação, a noção de "não-continuidade" do plantão foi compreendida como referência e não como modelo de atendimento.

Também é possível considerar que, havendo um único atendimento ou uma série deles, cada retorno pode ser pensado como um encontro distinto do anterior, mesmo quando os plantonistas são mantidos. Como Caio avaliou: "atender no plantão é sempre lidar com uma coisa nova que aparece".

Por essa via, outra singularidade deste estágio referiu-se a supervisão, conforme relato de Luiza:

O diferencial deste estágio é a forma como acontece a supervisão: todos juntos ouvindo a supervisão de outra pessoa. (...) Mesmo sendo em grupo eu não me senti exposta. (...) O supervisor não me pediu para abrir aquilo que era meu e colocar no grupo... vai muito da sua liberdade. Mas eu penso que o aprendizado é maior quando você abre e pode olhar para algo que é teu. Desse modo o grupo todo participa e se faz grupo: eu consigo entender quando é com o outro, assim como ele comigo.

Embora a supervisão possa ser individual, este trecho apontou para a riqueza dela acontecer prioritariamente num espaço comum, onde plantonistas e supervisores podem se ouvir e participar. Tomar parte na supervisão de outros colegas auxiliou a estagiária em suas próprias descobertas. Deste modo, a estagiária compreendeu que mesmo assuntos pessoais podem conduzir a temas de interesse coletivo à formação, na constituição de um espaço de compartilhamento de experiências.

Neste sentido, Luiza revelou o modo como os supervisores disponibilizaram-se aos estagiários: “ $a \mathrm{su}$ pervisão trabalha o aluno e não somente o relato do caso e eu considero isso um cuidado essencial. (...) Por isso é comum, depois da supervisão, aquela sensação de "eu deveria ter falado isso".

A supervisão ofereceu um espaço para o estagiário mostrar-se a partir de como foi afetado pelo outro, de modo que os supervisores puderam trabalhar alguns pressupostos que apareceram nas narrativas dos estagiários. Beatriz apresentou uma situação na qual o cliente não retornou ao plantão: "Eu reparei que ela não voltou e fiquei com a sensação de que o atendimento não foi bom. Ela pode não ter voltado por vários mo- tivos, mas talvez ela também tenha achado ruim, o que é bem plausível.". Porém, no diálogo com os supervisores outra leitura foi proposta: “... percebemos que poderia ser não só uma inabilidade nossa, mas uma resistência da pessoa. Eu retornei mais tranquila, pensando que talvez a pessoa tivesse o ritmo dela e não iria se abrir naquele momento.". Embora o plantão possa ser único, o retorno da cliente foi compreendido pela plantonista como principal parâmetro de avaliação do seu atendimento. Os supervisores marcaram como a ênfase nessa ideia poderia prejudicar o surgimento de outras compreensões.

Deste modo, a supervisão surgiu nos relatos como espaço privilegiado para o plantonista debruçar-se sobre o seu fazer, descobrindo-se e re-significando modos de atender. Neste sentido, este estágio revelou o modo como cada plantonista foi descobrindo o seu "jeito pessoal de atender".

Neste transitar por entre as falas, na tentativa de explicitar o sentido da experiência de estágio para estes quatro estudantes, histórias foram contadas. Nelas, tanto o plantão como o jeito pessoal de cada entrevistado deram-se a ver e puderam propiciar reflexões importantes sobre como a formação foi pensada e realizada neste projeto. Assim, atentando para o que foi desvelado nos relatos e nesta trajetória compreensiva, abrem-se novas reflexões, rumo a questões e caminhos possíveis.

\section{Alcances e impasses do plantão nos semestres iniciais}

Ousadamente apresentar o plantão aos estagiários sem uma explicitação prévia da perspectiva fenomenológica existencial ou junto a essas aulas revelou-se, neste percurso investigativo, ruptura que convidava o plantonista a constituir saberes de ofício a partir da própria experiência. Deste modo, "não bastaria um acúmulo de informações teóricas sobre este enfoque, sem uma compreensão experiencial do tipo de transformação de atitude que está aí em jogo.” (Sá, Azevedo Junior \& Leite, 2010, p. 137).

Os relatos evidenciaram que, inicialmente, os estagiários experienciaram essa ruptura de maneira a fazer uso dessa aparente falta de rigorosidade teórico científica para justificar posicionamentos prévios, arriscando manter-se no já sabido ou no senso-comum. Entretanto, embora tal oferta de estágio possa soar tentadora para quem deseja "colocar a mão na massa" desde cedo, o percurso no plantão foi marcado por conflitos e questionamentos constantes.

Neste sentido, o atendimento em dupla, a "supervisão de meio" e a supervisão logo após o atendimento foram o modo diferenciado encontrado pelo projeto para cuidar da formação do estagiário.

Ambas as supervisões apareceram como espaço privilegiado para o plantonista compreender o plantão a partir do modo como ele pôde compreender-se no atendimento, descobrindo o seu jeito de ser psicó- 
logo. A supervisão surgia ora como lugar reconfortante para o estagiário se situar após o atendimento, ora como espaço de discordâncias e incômodos, pelo qual o plantonista pôde entrar em contato com as vicissitudes que envolvem o exercício profissional. Alguns autores (Sá et al., 2010; Dutra, 2013) também marcam como a supervisão na abordagem fenomenológica existencial, muitas vezes, sustenta o desconforto e o silêncio como modo de provocar o plantonista, no sentido de convocá-lo a refletir sobre o atendimento a partir da perda das referências usuais (explicações teóricas ou do senso-comum) $)^{3}$. Assim, a perspectiva fenomenológica existencial apresentou-se pela ação do supervisor em compreender como o estagiário se encontrava afetado pelo atendimento.

Por essa via, a "supervisão de meio", também evidenciou como o atendimento em plantão se diferencia da proposta de sessões psicoterápicas (50 min.), podendo ser único, o que demandava formulações criativas do projeto. Em média os atendimentos duravam uma hora e meia, contando a escuta e intervenções iniciais, a supervisão de meio e o retorno para fechamento. Neste sentido, a clínica-escola pode e deve preparar o estudante para um contexto diverso do consultório, mais marcadamente em instituições da rede pública de saúde e/ou de educação.

Aliás, o fato desta supervisão acontecer em grupo também foi um diferencial. Por um lado, isso pode marcar uma precarização do estágio, quando se sobrecarrega o psicólogo com um número elevado de estudantes a serem supervisionados em um curto espaço de tempo. Entretanto, a supervisão em grupo contemplou uma rica dimensão da comunicação, no trânsito entre aquilo que é singular e coletivo. Identificar-se e estranhar-se perante o que é dito por outro marcaram uma riqueza à aprendizagem na escuta da experiência do colega sendo supervisionado, de modo a reverberar nas próprias vivências.

Em relação à dupla de atendimento formada com psicólogos ou colegas dos últimos semestres, os estagiários revelaram como foram modificados a partir do modo como estes colegas se colocaram no atendimento. Alguns apontaram como ficou evidente, em muitas situações, que não era preciso dar respostas ao cliente e nem tentar tirá-lo do sofrimento, mas de estar junto, propiciando contato com estas questões de maneira a explicitar o modo de ser do cliente a ele mesmo. Segundo Morato (2013), tal ação psicológica busca inspiração na compreensão fenomenológica da solicitude em seu modo liberador, pelo qual "compreende-se o outro diante de suas próprias possibilidades, encarregando-o de seu poder-ser para

\footnotetext{
3 Tais considerações me remetem a pensar no supervisor como aquele que "circulando em torno" do estagiário, dá a ver as marcas que este carrega do atendimento, algumas já percebidas, outras ainda encobertas; de modo semelhante ao conto do Arlequim, de Michel Serres (1993), no qual a experiência deixa as suas marcas na personagem. Assim aproximados, o "plantonista-arlequim" pode reconhecer-se marcado pelo "percurso" do atendimento, recorrendo então, ás vezes à revelia, ao olhar do outro para constituir-se psicólogo: viajante mestiçado pelas paisagens e histórias que lhe vieram ao encontro.
}

conduzir-se em dada situação, pertinentemente a seu ser-no-mundo.” (Morato, 2013, p. 52).

$\mathrm{O}$ atendimento em plantão, levando os estagiários a improvisarem diante do inesperado, também revelou, mesmo que timidamente, o surgimento da linguagem poética. Nesta direção, libertar a palavra do âmbito do raciocínio explicativo, com seus significados já dados de antemão e gastos pelo falatório, não significou "fazer poesia" ou erudição, mas de buscar um dizer que desvelasse o sentido de algo. Era um modo de, simultaneamente, nomear aquilo que "tocava" o plantonista e manter o espaço de liberdade do cliente, que poderia compreender o que se tentou comunicar ou não (Pompeia \& Sapienza, 2011).

Por essa via, a experiência profissional, como supervisor de grupos, vem mostrando que os alunos e participantes chegam com repertórios de expressão, ideais e ações e de vocabulário cada vez mais restritos. Apresentam-se como que murchos, desgastados, desbastados, cansados. Suas falas parecem estar destituídas da voz do dono; mas, pelo cultivo do falar, apresentam-se sensivelmente outras. Seria isso o que se refere como aprendizagem significativa?

A aprendizagem significativa refere-se à criação ou resgate de sentido para "falas" a partir da própria experiência, geralmente esquecida ou como "em branco", conduzindo-as a caírem num lugar comum do "falar por falar". É abrir possibilidades a modos como o sujeito se apresenta disponível no mundo, ou seja, ressignificar significados como possibilidade de outro sentido. Diz respeito à reflexão na experiência e não sobre a experiência. Na ausência de situação para a ocorrência de criação de significado sentido, falas não se dirigem para a abertura a outras possibilidades, articulações, sentido (Gendlin, 1973).

A aprendizagem significativa em ação, por outro lado, também pode se referir ao fenômeno vivido em supervisões, e que passou a ser denominado como espelho mágico: falando do cliente, há momentos em que se percebe no grupo o mesmo movimento do cliente vivido pelo estagiário no atendimento. Falar de nosso próprio grupo, o de supervisão, tematizando e esclarecendo nossas próprias questões, pode apresentar-se como meio de compreender tanto a nossa experiência ali vivida quanto esclarecer aspectos do cliente.

Desse modo, é possível dizer como foi a apreensão da experiência, a comunicação da afetação, bem como encontrar o sentido da experiência, na medida em que se articula o que é explícito (teórico) com o que já é tácito (vivido) em qualquer ação em situação de trabalho.

Diante dessas considerações, é possível afirmar que a formação realizada neste estágio de atendimento em plantão psicológico apresentou-se como formar-ação, aprendizagem pela experiência como possibilidade de "fazer-saber" pelos próprios pés, junto a outros: pés que trilham fazendo caminho ao trilhar. 


\section{Referências}

Aun, H. A. (2005). Trágico avesso do mundo: narrativas de uma prática psicológica numa instituição para adolescentes infratores. (Dissertação de Mestrado). Universidade de São Paulo, São Paulo, SP.

Benjamin, W. (1994). Magia e técnica, arte e política: ensaios sobre literatura e história da cultura. (Obras Escolhidas, Vol, 1). (7a ed). São Paulo, SP: Brasiliense.

Bourdieu, P. (Org.). (1997). A miséria do mundo. (3a ed.). Petrópolis, RJ: Vozes.

Câmera de Educação Superior-Brasil, Conselho Nacional de Educação (2004, 7 de maio). Resolução $\mathrm{n}^{\circ}$ 8. Diretrizes curriculares para os cursos de psicologia. Brasília, DF: CNE/MEC.

Câmera de Educação Superior-Brasil, Conselho Nacional de Educação (2011, 15 de março). Resolução $\mathrm{n}^{\circ} 5$. Diretrizes curriculares para os cursos de psicologia. Brasília, DF: CNE/MEC.

Cardoso, I. (Org.). (1997). Utopia e mal-estar na cultura: perspectivas psicanalíticas. São Paulo, SP: Hucitec.

Critelli, D. M. (1996). Analítica do sentido: uma aproximação e interpretação do real de orientação fenomenológica. São Paulo, SP: EDUC: Brasiliense.

Dutra, E. (2013). Formação do psicólogo clínico na perspectiva fenomenológico-existencial: dilemas e desafios em tempos de técnicas. Revista da Abordagem Gestáltica, 19(2), 205-211.

Figueiredo, L. C. M. (1993). Sob o signo da multiplicidade. Cadernos de Subjetividade (PUC-SP), 1, 89-95.

Figueiredo, L. C. \& de Santi, P. L. R. (2003). Psicologia, uma (nova) introdução; uma visão histórica da psicologia como ciência. ( $2^{\mathrm{a}}$ ed.). São Paulo, SP: EDUC.

Gadamer, H. (1997). Verdade e método. Petrópolis, RJ: Vozes.

Gendlin, E. T. (1973). Experiential phenomenology. In M. Natanson (Org.). Phenomenology and the social sciences (p. 66-79). Evanston, IL: Northwest University Press.

Quintana, M. (1988). Diário poético 89. Rio de Janeiro, RJ: Globo.

Mahfoud, M. (1999). Plantão psicológico na escola: uma experiência. In H. T. P. Morato (Org.). Aconselhamento psicológico centrado na pessoa: novos desafios (p. 145-160). São Paulo, SP: Casa do Psicólogo.
Meihy, J. C. S. B. (1991). Canto de morte kaiowá: história oral de vida. São Paulo: Loyola.

Morato, H. T. P. (Org.). (1999). Aconselhamento psicológico centrado na pessoa: novos desafios. São Paulo, SP: Casa do Psicólogo.

Morato, H. T. P. (2009). Atenção psicológica e aprendizagem significativa. In H. T. P. Morato, C. L. B. T. Barreto \& A. P. N. Nunes (Orgs.). Aconselhamento psicológico numa perspectiva fenomenológica existencial: uma introdução (p. 2239). Rio de Janeiro, RJ: Guanabara Koogan.

Morato, H. T. P. (2013). Algumas considerações da fenomenologia existencial para a ação psicológica na prática e na pesquisa em instituições. In C. L. B. T. Barreto, H. T. P. Morato \& M. T. Caldas (Orgs.). Prática psicológica na perspectiva fenomenológica (p. 51-76). Rio de Janeiro, RJ: Juruá.

Pompeia, J. A., \& Sapienza, B. T. (2011). Os dois nascimentos do homem: escritos sobre terapia e educação na era da técnica. Rio de Janeiro, RJ: Via Verita.

Sá, R. N., Azevedo Junior, O., \& Leite, T. L. (2010). Reflexões fenomenológicas sobre a experiência de estágio e supervisão clínica em um serviço de psicologia aplicada universitário. Revista $d a$ Abordagem Gestáltica, 16(2), 135-140.

Serres, M. (1993). Filosofia mestiça. Rio de Janeiro, RJ: Nova Fronteira.

Yehia, G. Y. (1996). Clínica-Escola: Atendimento ao estagiário ou atendimento ao cliente? Coletâneas da ANPEPP 1(9), 109-118. Campinas: Alínea.

André Prado Nunes (Orcid: 0000-0001-8498-2758) é Doutor em Psicologia Escolar e do Desenvolvimento Humano pela Universidade de São Paulo. Colaborador, pesquisador e supervisor clínico no Laboratório de Estudos e Prática em Psicologia Fenomenológica Existencial da Universidade de São Paulo (LEFE-IPUSP). Co-organizador do livro "Aconselhamento Psicológico numa perspectiva Fenomenológica Existencial"; e autor de 13 artigos e trabalhos científicos. Atua em consultório particular e trabalha há 10 anos com docência no ensino superior (Universidade de São Paulo). andrepn@usp.br

Henriette Tognetti Penha Morato (Orcid: 0000-00021360-1169) possui Doutorado em Psicologia Escolar e do Desenvolvimento Humano pela Universidade de São Paulo. Atualmente é Professora Associada do Instituto de Psicologia da Universidade de São Paulo. Realizou pós-doutorado na Universidade Paris 7 entre 2005 e 2006, com pesquisa realizada na Universidade de Firenze. Atua na área de psicologia, 
com ênfase em psicologia do desenvolvimento humano. Coordena o Laboratório de Estudos em Fenomenologia Existencial e Prática em Psicologia (LEFE) do Instituto de Psicologia da Universidade de São Paulo. Coordenadora Técnica do Centro Escola do Instituto de Psicologia da USP (IPUSP). Endereço Institucional: Avenida Professor Mello de Morais, 1721 - Butantã, São Paulo - SP, 05508-030. Telefone: 3091-4285. E-mail: lefe@usp.br.

Recebido em 01.08.17

Primeira decisão editorial em 17.08 .18

Aceito em 03.10.18 